Article

\title{
Reduction of Bromo- and Iodo-2,6-bis(diphenylphosphanylmethyl)benzene with Magnesium and Calcium
}

\author{
Alexander Koch, Sven Krieck, Helmar Görls and Matthias Westerhausen * \\ Institute of Inorganic and Analytical Chemistry, Friedrich Schiller University of Jena, 07745 Jena, Germany; \\ koch.alexander@uni-jena.de (A.K.); sven.krieck@uni-jena.de (S.K.); helmar.goerls@uni-jena.de (H.G.) \\ * Correspondence: m.we@uni-jena.de; Tel.: +49-3641-9-48110 \\ Academic Editor: Lee J. Higham \\ Received: 1 November 2016; Accepted: 25 November 2016; Published: 1 December 2016
}

\begin{abstract}
Arylmagnesium and -calcium reagents are easily accessible; however, ether degradation processes limit storability, especially of the calcium-based heavy Grignard reagents. Ortho-bound substituents with phosphanyl donor sites usually block available coordination sites and stabilize such complexes. The reaction of bromo-2,6-bis(diphenylphosphanylmethyl)benzene (1a) with magnesium in tetrahydrofuran yields $\left[\mathrm{Mg}\left\{\mathrm{C}_{6} \mathrm{H}_{3}-2,6-\left(\mathrm{CH}_{2} \mathrm{PPh}_{2}\right)_{2}\right\}_{2}\right]$ (2) after recrystallization from 1,2-dimethoxyethane. However, the similarly performed reduction of bromo- (1a) and iodo-2,6-bis(diphenylphosphanylmethyl)benzene (1b) with calcium leads to ether cleavage and subsequent degradation products. $\alpha$-Deprotonation of tetrahydrofuran (THF) yields 1,3-bis(diphenylphosphanylmethyl)benzene. Furthermore, the insoluble THF adducts of dimeric calcium diphenylphosphinate halides, $\left[(\text { thf })_{3} \mathrm{Ca}(\mathrm{X})\left(\mu-\mathrm{O}_{2} \mathrm{PPh}_{2}\right)\right]_{2}[\mathrm{X}=\mathrm{Br}(\mathbf{3 a}), \mathrm{I}(\mathbf{3 b})]$, precipitate verifying ether decomposition and cleavage of $\mathrm{P}-\mathrm{C}$ bonds. Ether adducts of calcium halides (such as $\left.\left[(\mathrm{dme})_{2}(\mathrm{thf}) \mathrm{CaBr}_{2}\right](4)\right)$ form, supporting the initial Grignard reaction and a subsequent Schlenk-type dismutation reaction.
\end{abstract}

Keywords: Grignard reagent; arylmagnesium halide; phosphinates; calcium phosphinates; direct synthesis; ether degradation; calcium bromide

\section{Introduction}

The Grignard reaction is a widely used synthesis of organomagnesium compounds for diverse applications such as metalation of $\mathrm{H}$-acidic compounds (magnesiation), group transfer (salt metathesis reactions), addition to, e.g., ketones and aldehydes (synthesis of alcohols), and C-C coupling reactions (Kumada cross coupling). The insertion of magnesium into a carbon-halogen bond can be accompanied by ether cleavage with the initial $\alpha$ - or $\beta$-deprotonation step or a radical mechanism [1,2]. The organocalcium halides (heavy Grignard reagents) tend much more to degrade ethers and only selected arylcalcium [3-10] and trimethylsilylmethylcalcium complexes [11] are easily prepared via the direct synthesis.

Enhancement of steric demand of the aryl groups does not necessarily enhance the stability of the arylcalcium halides. Bulky substituents such as tert-butyl groups in ortho-position destabilize the arylcalcium halides significantly, finally leading to 2,5-dimethyl-2,5-bis[3,5-di(tert-butyl)phenyl]hexane $[7,10]$. In order to stabilize magnesium- and calcium-based Grignard reagents, ortho-substituents with Lewis basic donor atoms such as phosphanes in the side arms could repel intramolecular side reactions and ether degradation by blocking of the coordination sites at the alkaline earth cations. One would expect that soft phosphorus bases bind less strongly to the rather hard magnesium and calcium cations than hard oxygen and nitrogen bases. In addition, phosphanes can only act as pure $\sigma$-donors. Due to 
this fact the phosphane bases are commonly incorporated into the anions leading to multidentate anions. Nevertheless, a variety of phosphane complexes of magnesium (see e.g., [12-16]) and calcium (see e.g., [15-19]) have been isolated and structurally studied. In order to stabilize magnesium- and calcium-based Grignard reagents, phosphanylmethyl substituents in ortho-position of the arylalkaline earth metal halides seem to be a suitable choice. Müller and coworkers already investigated solvent-free [Li- $\left.\mathrm{C}_{6} \mathrm{H}_{3}-2,6-\left(\mathrm{CH}_{2} \mathrm{PMe}_{2}\right)_{2}\right]_{2}(\mathbf{A})$ and $\left[\mathrm{Mg}\left\{\mathrm{C}_{6} \mathrm{H}_{3}-2,6-\left(\mathrm{CH}_{2} \mathrm{PMe}_{2}\right)_{2}\right\}_{2}\right]$ (B, Scheme 1; $\mathrm{Mg}-\mathrm{P} 276.1(1)$ and 277.0(1) pm, Mg-C 221.6(1) pm) with ortho-bound dimethylphosphanylmethyl side arms [14]. The bite of the 2,6-bis(dimethyl-phosphanylmethyl)phenyl base is flexible and, hence, this ligand is able to encapsulate cations with various radii.

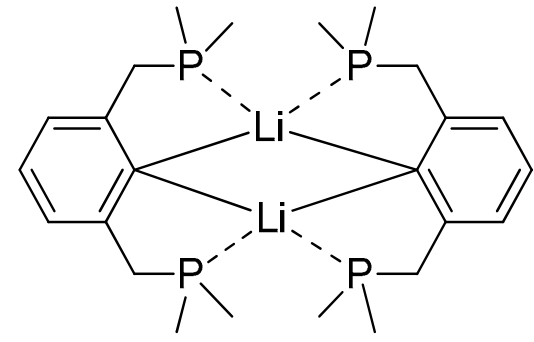

A

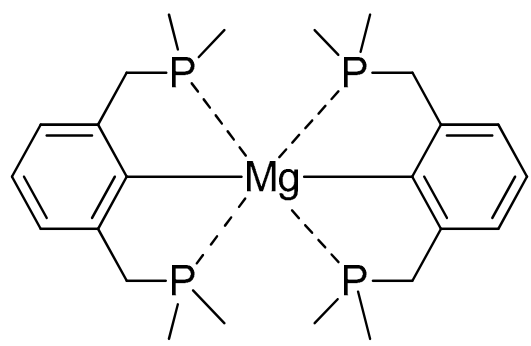

B

Scheme 1. Representation of $\left[\mathrm{Li}-\mathrm{C}_{6} \mathrm{H}_{3}-2,6-\left(\mathrm{CH}_{2} \mathrm{PMe}_{2}\right)_{2}\right]_{2}(\mathrm{~A})$; and $\left[\mathrm{Mg}\left\{\mathrm{C}_{6} \mathrm{H}_{3}-2,6-\left(\mathrm{CH}_{2} \mathrm{PMe}_{2}\right)_{2}\right\}_{2}\right](\mathbf{B})$.

We assumed that the phosphanyl bases might be suitable donor sites in organocalcium chemistry. Due to the larger ionic radius of $\mathrm{Ca}^{2+}$ compared to $\mathrm{Mg}^{2+}$, the softer cation $\mathrm{Ca}^{2+}$ should prefer the softer phosphorus-based Lewis bases, enabling the isolation of ether-free diarylcalcium. For comparison reasons we intended to prepare the magnesium and calcium complexes with bis(phosphanylmethyl)-substituted phenyl groups.

\section{Results}

\subsection{Reduction of Bromo-2,6-bis(diphosphanylmethyl)benzene with Magnesium}

For the reduction of sterically shielded bromo-2,6-bis(diphenylphosphanylmethyl)benzene (1a), a 1:1 mixture of Rieke magnesium and magnesium turnings was used in THF. This suspension was heated under reflux, and iodine crystals had to be added to maintain the reduction reaction. Monitoring of the reaction by ${ }^{31} \mathrm{P}\left\{{ }^{1} \mathrm{H}\right\}$ NMR spectroscopy showed four resonances at $\delta=-10.6$, $-13.2,-15.5$, and $-22.1 \mathrm{ppm}$ (Figure 1). The first two signals can be assigned to 2,6-bis(diphenyl phosphanylmethyl)benzene and 1a, respectively. At $4{ }^{\circ} \mathrm{C}$ an amorphous precipitate formed which was dissolved with 1,2-dimethoxyethane. Repeated cooling to $4{ }^{\circ} \mathrm{C}$ yielded [(thf $\left.)_{2} \mathrm{MgBr}_{2}\right]$ and crystalline bis[2,6-bis(diphenylphosphanylmethyl)phenyl]magnesium (2) with a chemical shift of $\delta\left({ }^{31} \mathrm{P}\left\{{ }^{1} \mathrm{H}\right\}\right)=-15.6 \mathrm{ppm}$. Addition of 1,4-dioxane shifted the Schlenk equilibrium toward the homoleptic derivatives $\mathrm{MgR}_{2}$ and $\mathrm{MgBr}_{2}$ due to quantitative precipitation of [(diox) $\left.\mathrm{MgBr}_{2}\right]_{\infty}$. The resonance at $\delta=-22.1$ vanished and complex 2 was isolated with moderate yield (Equation (1)). The presence of significant amounts of 2,6-bis(diphenylphosphanylmethyl)benzene underlines the relevance of ether degradation, especially because drastic reaction conditions (such as boiling THF) are required to expedite the Grignard reaction. It is remarkable that the Grignard reagent 2 crystallizes from ethereal solvents without ligated ether molecules, even in the presence of bidentate 1,2-dimethoxyethane. 


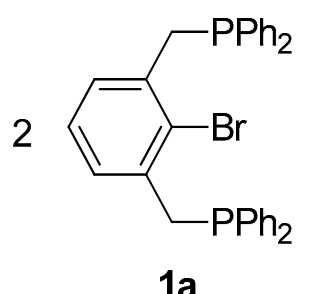

$+2 \mathrm{Mg}$

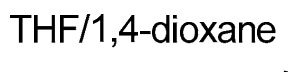

- (diox) $\mathrm{MgBr}_{2}$

1 a

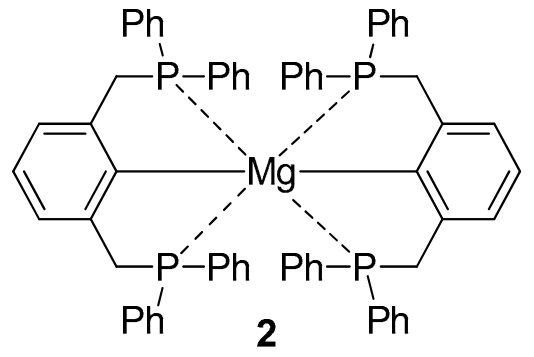

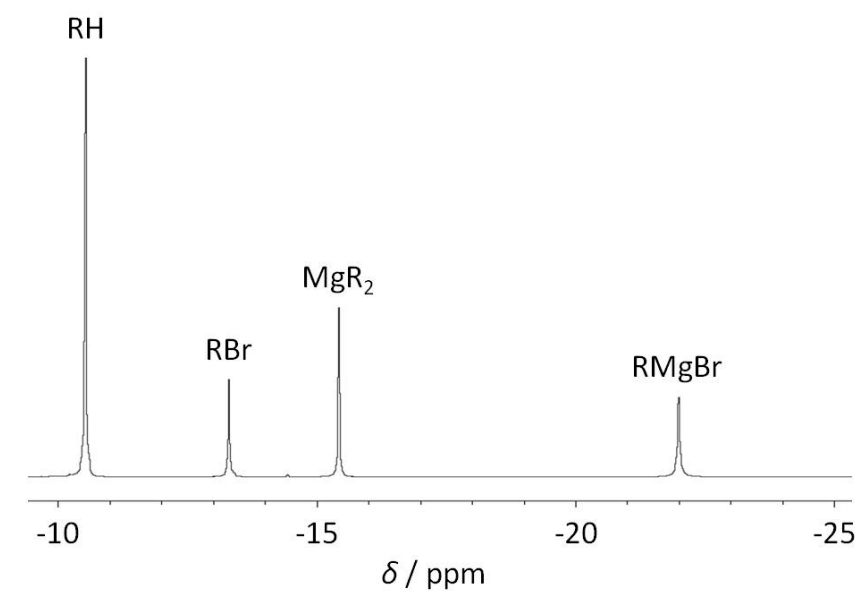

Figure 1. ${ }^{31} \mathrm{P}\left\{{ }^{1} \mathrm{H}\right\}$ NMR spectrum of the Grignard reaction of bromo-2,6-bis(diphenylphosphanyl methyl)benzene (1a, $\mathrm{RBr}$ ) with magnesium in tetrahydrofuran (see text, $\mathrm{R}=\mathrm{C}_{6} \mathrm{H}_{3}-2,6-\left(\mathrm{CH}_{2} \mathrm{PPh}_{2}\right)_{2}$; $162 \mathrm{MHz}, 25^{\circ} \mathrm{C} ;\left[\mathrm{D}_{6}\right]$ benzene was added to the reaction solution for the NMR measurement).

The molecular structures and atom numbering schemes of $\mathbf{1 a}$ and $\mathbf{2}$ are depicted in Figures 2 and 3 , respectively. In bromo-2,6-bis(diphenylphosphanylmethyl)benzene (1a) the phosphanyl side arms are turned outside and hydrogen atoms of the methylene moieties (at C7 and C8) point toward the bromine atom. The $\mathrm{P}-\mathrm{C}$ bond lengths to the $\mathrm{sp}^{3}$ hybridized methylene groups $\mathrm{C} 7$ and $\mathrm{C} 8$ are slightly larger than the $\mathrm{P}-\mathrm{C}$ values to the phenyl groups with $\mathrm{sp}^{2}$ hybridized ipso-carbon atoms. The phosphorus atoms are in pyramidal environments with angle sums of $300.4^{\circ}$ and $304.4^{\circ}$ for $\mathrm{P} 1$ and $\mathrm{P} 2$, respectively. The $\mathrm{C} 2-\mathrm{C} 1-\mathrm{C} 6$ bond angle of the ipso-carbon atom $\left(123.4(2)^{\circ}\right)$ is slightly larger than $120^{\circ}$ due to the positive charge on $\mathrm{C} 1$. The umpolung at this carbon via substitution of bromine by magnesium leads to narrower angles at the ipso-carbon atoms in complex 2 (C2-C1-C6 $115.8(2)^{\circ}$ and $\left.\mathrm{C} 34-\mathrm{C} 33-\mathrm{C} 38115.6(2)^{\circ}\right)$ due to electrostatic repulsion between the negatively charged electron pair and the neighboring bonds to the ortho-carbon atoms. The $\mathrm{Mg} 1-\mathrm{C}$ bond lengths of 219.3(3) and 218.3(3) pm lie in the expected range as also observed for other organomagnesium complexes [20-24]. The magnesium atom is rather small for the bite of the anionic ligand. Therefore, each phosphanyl-substituted aryl group additionally forms a strong Mg-P bond (Mg1-P1 269.2(1), Mg1-P4 268.9(1) pm) and a significantly longer bond (Mg1-P2 296.1(1), Mg1-P3 286.3(1) pm). The formation of coordinative Mg-P bonds increases the angle sums at the phosphorus atoms, taking only the carbon atoms into account (P1: $\left.311.1^{\circ}, \mathrm{P} 2: 308.7^{\circ}, \mathrm{P} 3: 309.3^{\circ}, \mathrm{P} 4: 311.5^{\circ}\right)$. Despite the attraction between the magnesium ion and the phosphanyl bases, the $\mathrm{P}-\mathrm{C}_{\mathrm{CH}}-\mathrm{C}_{\text {ortho }}$ bond angles are still larger than the tetrahedral angle due to intramolecular repulsion at the periphery of the complex. This repulsion is also the reason for the peculiar coordination behavior with drastically different $\mathrm{Mg}-\mathrm{P}$ bonds because the dimethylphosphanylmethyl-substituted derivative B (see Scheme 1) exhibits a symmetric coordination mode [14]. 


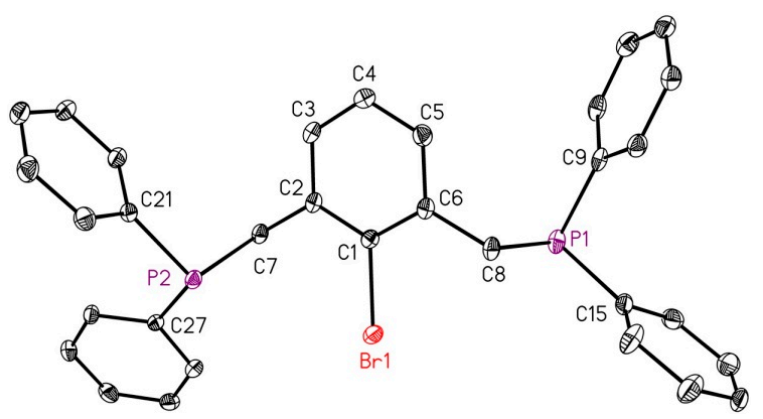

Figure 2. Molecular structure and atom numbering scheme of bromo-2,6-bis(diphenylphosphanyl methyl)benzene (1a). The ellipsoids represent a probability of 30\%; $\mathrm{H}$ atoms are shown with arbitrary radii. Selected bond lengths (pm): Br1-C1 191.8(3), P1-C8 186.1(3), P1-C9 184.2(3), P1-C15 183.6(3), P2-C7 186.5(3), P2-C21 183.1(3), P2-C27 184.0(3); angles ( $\left.{ }^{\circ}\right)$ : C8-P1-C9 99.4(1), C8-P1-C15 101.0(1), C9-P1-C15 100.1(1), C7-P2-C21 103.5(1), C7-P2-C27 102.2(1), C21-P2-C27 102.2(1), Br1-C1-C2 117.9(2), Br1-C1-C6 118.7(2), C2-C1-C6 123.4(2), C2-C7-P2 112.3(2), C6-C8-P1 110.8(2).

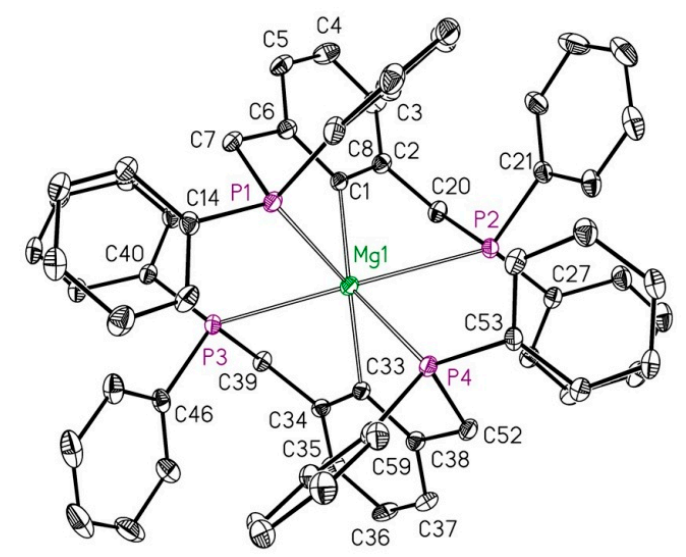

Figure 3. Molecular structure and atom numbering scheme of bis(2,6-bis(diphenylphosphanyl methyl)phenyl)magnesium (2). The ellipsoids represent a probability of 30\%; $\mathrm{H}$ atoms are omitted for the sake of clarity. Selected bond lengths (pm): Mg1-C1 219.3(3), Mg1-C33 218.3(3), Mg1-P1 269.2(1), Mg1-P2 296.1(1), Mg1-P3 286.3(1), Mg1-P4 268.9(1), P1-C7 183.9(3), P1-C8 183.3(3), P1-C14 182.7(3), P2-C20 185.1(3), P2-C21 182.5(3), P2-C27 183.3(3), P3-C39 184.5(3), P3-C40 183.1(3), P3-C46 182.3(3), P4-C52 184.3(3), P4-C53 182.4(3), P4-C59 183.1(3); angles ( $\left.{ }^{\circ}\right)$ : C1-Mg1-C33 129.2(1), C1-Mg1-P1 76.88(7), C1-Mg1-P2 72.63(7), C1-Mg1-P3 89.57(7), C1-Mg-P4 143.91(7), C33-Mg1-P1 145.56(8), C33-Mg1-P2 88.14(7), C33-Mg1-P3 73.32(7), C33-Mg1-P4 76.65(7), P1-Mg1-P2 124.40(4), P1-Mg1-P3 86.58(3), P1-Mg1-P4 93.55(3), P2-Mg1-P3 137.24(4), P2-Mg1-P4 85.40(3), P3-Mg1-P4 124.98(4), C2-C1-C6 115.8(2), C34-C33-C38 115.6(2).

\subsection{Reduction of 2,6-bis(diphosphanylmethyl)phenyl Halides with Calcium}

Due to the fact that the bite of the 2,6-bis(diphenylphosphanylmethyl)phenyl group is too large to symmetrically bind to $\mathrm{Mg}^{2+}$ ions, larger alkaline earth ions might be more adequate for this aryl substituent. Therefore, bromo-2,6-bis(diphenylphosphanylmethyl)benzene (1a) and activated calcium powder were stirred at room temperature in THF for six hours. In order to accelerate the reduction reaction, a few crystals of iodine were added. Filtration and storage of the filtrate at $4{ }^{\circ} \mathrm{C}$ yielded crystals of the calcium diphenylphosphinate bromide, $\left[(\text { thf })_{3} \mathrm{Ca}(\mathrm{Br})\left(\mu-\mathrm{O}_{2} \mathrm{PPh}_{2}\right)\right]_{2}(3 \mathrm{a})$. Rather poor crystal quality and heavily disordered thf ligands limit the discussion of the molecular structure and only a motif was refined, which is shown in Figure 4 . The connectivity can be elucidated; however, a discussion of the structural parameters can only briefly be offered for the inner fragment. The calcium atoms are in distorted octahedral environments with a Ca1-Br1 distance of 296.8(2) pm. The diphenylphosphinate anions occupy bridging positions leading to a dinuclear complex with a central eight-membered $\mathrm{Ca}_{2} \mathrm{P}_{2} \mathrm{O}_{4}$ ring containing a crystallographic center of symmetry. 
The Ca1-O1A/2 bonds of 225.5(6) and 221.6(5) pm are rather short due to strong electrostatic attractions. The P1-O1/2-Ca1A/1 bond angles of $142.3(3)^{\circ}(\mathrm{O} 1)$ and $175.3(4)^{\circ}(\mathrm{O} 2)$ are large and differ significantly, supporting mainly non-directional ionic interactions between calcium and the anions.

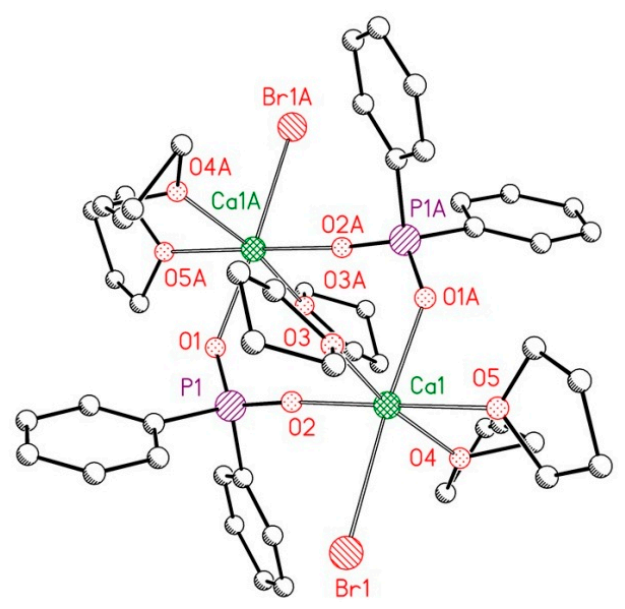

Figure 4. Structural motif and atom numbering scheme of $\left[(\operatorname{thf})_{3} \mathrm{Ca}(\mathrm{Br})\left(\mu-\mathrm{O}_{2} \mathrm{PPh}_{2}\right)\right]_{2}(3 \mathbf{a})$. Symmetry related atoms are marked with the letter " $\mathrm{A}$ ". The ellipsoids represent a probability of $30 \%$; the thf ligands are drawn with arbitrary radii. $\mathrm{H}$ atoms and disordering of the thf ligands are not shown. Bond lengths of the inner core (pm): Ca1-Br1 296.8(2), Ca1-O1A 225.5(6), Ca1-O2 221.6(5), Ca1-O3 234.9(7), Ca1-O4 237.6(7), Ca1-O5 238.8(5), P1-O1 150.4(5), P1-O2 150.3(5), P1-C1 180.6(9), P1-C7 180.0(8); angles $\left(^{\circ}\right)$ : O1A-Ca1-O2 94.4(2), O1-P1-O2 119.1(3), P1-O1-Ca1A 142.3(3), P1-O2-Ca1 175.3(4), Br1-Ca1-O1A 174.0(1), Br1-Ca1-O2 91.4(2).

After addition of 1,2-dimethoxyethane (DME) and storage in a refrigerator, another crop of crystals of $\left[(\mathrm{dme})_{2}(\mathrm{thf}) \mathrm{CaBr}_{2}\right](4)$ was obtained. The molecular structure and numbering scheme of $\mathrm{C}_{2}$ symmetric 4 are depicted in Figure 5. The calcium atoms are in a distorted pentagonal bipyramidal environment with a Ca1-Br1 distance of 288.86(2) $\mathrm{pm}$. Due to steric hindrance between the methoxy groups of the dme ligands, the Ca1-O1 bond $(249.0(1) \mathrm{pm})$ is slightly elongated compared to the Ca1-O3 distance to the thf ligand $(238.0(1) \mathrm{pm})$. The bulkiness of these methoxy groups are also responsible for the non-linearity of the Br1-Ca1-Br1A moiety $\left(171.07(2)^{\circ}\right)$.

The product diversity of the reduction of bromo-2,6-bis(diphenylphosphanylmethyl)benzene (1a) with calcium hints toward fast ether degradation processes. The identification of calcium bromide verifies the initial formation of the heavy Grignard reagent Aryl-Ca-Br. This complex deprotonates THF yielding 2,6-bis(diphenylphosphanylmethyl)benzene that has been observed by ${ }^{31} \mathrm{P}\left\{{ }^{1} \mathrm{H}\right\} \mathrm{NMR}$ spectroscopy. The isolation of $\left[(\mathrm{thf})_{3} \mathrm{Ca}(\mathrm{Br})\left(\mu-\mathrm{O}_{2} \mathrm{PPh}_{2}\right)\right]_{2}(3 \mathrm{a})$ from these reduction reactions proves that the $\mathrm{P}-\mathrm{C}$ bond to the methylene unit has been cleaved, finally leading to the diphenylphosphinate anions. Earlier findings already demonstrated that oxide ions can be trapped in calcium cage compounds in the absence of low-valent phosphorus species [25-28]. In summary, the very reactive calcium-based heavy Grignard reagents quickly attack the ether molecules, leading to arene and diverse ether degradation products. Attempts to isolate arylcalcium bromide failed due to the fast decomposition reactions.

Based on our experience that iodoarenes react much more readily than bromoarenes and in order to accelerate the formation of the heavy Grignard reagent, we reacted excess of activated calcium with iodo-2,6-bis(diphenylphosphanylmethyl)benzene (1b) in tetrahydrofuran at room temperature. A ${ }^{31} \mathrm{P}\left\{{ }^{1} \mathrm{H}\right\} \mathrm{NMR}$ spectrum, recorded after a few hours, already showed primarily 2,6-bis(diphenylphosphanylmethyl)benzene. Storage of the reaction solution at $-40{ }^{\circ} \mathrm{C}$ led to crystallization of $\left[(\text { thf })_{3} \mathrm{Ca}(\mathrm{I})\left(\mu-\mathrm{O}_{2} \mathrm{PPh}_{2}\right)\right]_{2}(3 \mathbf{b}$, Figure 6$)$; a motif of this compound has been reported earlier $[29,30]$. In analogy to $3 \mathbf{a}$, the central feature is a centrosymmetric eight-membered $\mathrm{Ca}_{2} \mathrm{P}_{2} \mathrm{O}_{4}$ ring with an average $\mathrm{Ca}-\mathrm{O}$ distance of $224.3 \mathrm{pm}$. Due to a weaker electrostatic attraction, the $\mathrm{Ca}-\mathrm{O}_{\text {thf }}$ bonds to the tetrahydrofuran ligands are elongated and a mean value of $238.7 \mathrm{pm}$ is observed. The rather small $\mathrm{Ca}-\mathrm{O}_{\text {thf }}$ distances support lack of steric strain in this compound. The rather large P1-O1/2-Ca1/1A 
bond angles of 165.2(3) (O1) and $146.7(2)^{\circ}$ hint toward dominating electrostatic interactions between calcium ions and phosphinate anions and negligible covalent contributions. The phosphorus atom is in a distorted tetrahedral environment, with the largest angle being O1-P1-O2 with a value of $119.3(2)^{\circ}$. The Ca1-I1 bond length of 318.7(1) pm lies in the upper region as also observed for ether adducts of phenylcalcium iodide and calcium diiodide [31].

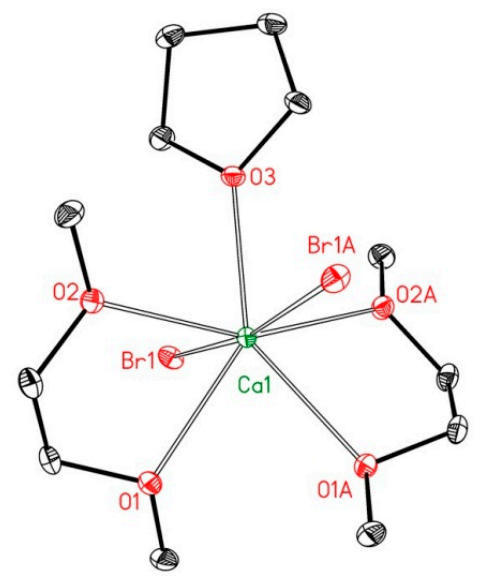

Figure 5. Molecular structure and atom numbering scheme of $\left[(\mathrm{dme})_{2}(\mathrm{thf}) \mathrm{CaBr}_{2}\right](4)$. Symmetry related atoms are marked with the letter " $\mathrm{A}$ ". The ellipsoids represent a probability of $30 \% ; \mathrm{H}$ atoms are neglected for clarity reasons. Selected bond lengths (pm): Ca1-Br1 288.86(2), Ca1-O1 249.0(1), Ca1-O2 243.4(1), Ca1-O3 238.0(1); angles $\left(^{\circ}\right)$ : Br1-Ca1-Br1A 171.07(2), Br1-Ca1-O1 80.03(3), Br1-Ca1-O2 94.07(3), Br1-Ca1-O3 85.535(8).

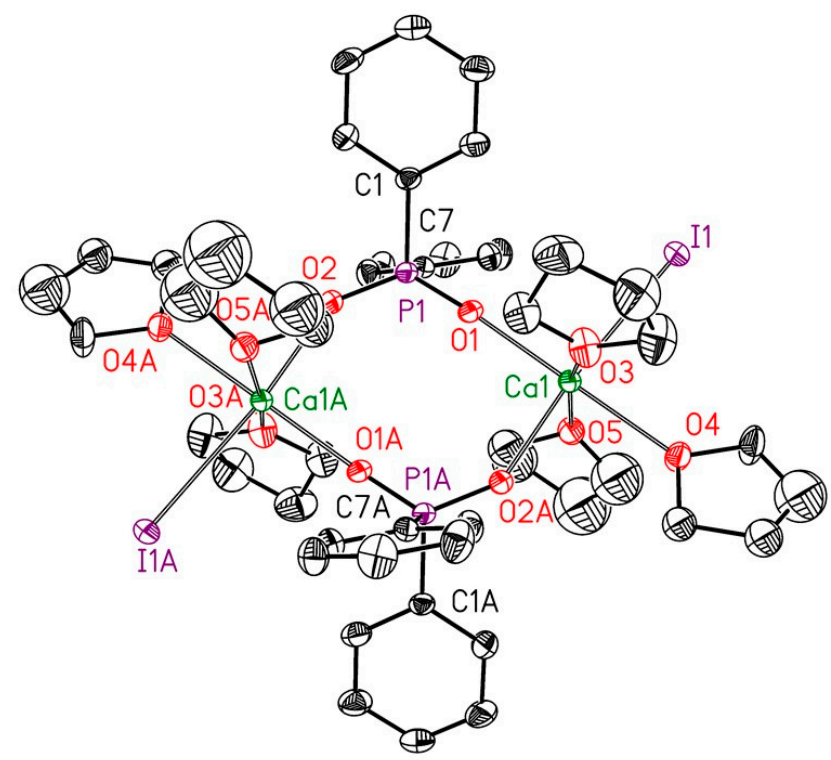

Figure 6. Molecular structure and atom numbering scheme of $\left[(\operatorname{thf})_{3} \mathrm{Ca}(\mathrm{I})\left(\mu-\mathrm{O}_{2} \mathrm{PPh}_{2}\right)\right]_{2}(3 \mathbf{b})$. Symmetry related atoms are marked with the letter " $\mathrm{A}$ ". The ellipsoids represent a probability of $30 \% ; \mathrm{H}$ atoms and disordering of the thf ligands are not shown. Bond lengths of the inner core (pm): Ca1-I1 318.7(1), Ca1-O1 222.7(4), Ca1-O2A 225.9(4), Ca1-O3 236.8(5), Ca1-O4 240.2(4), Ca1-O5 239.0(4), P1-O1 150.4(4), P1-O2 150.3(4), P1-C1 181.0(5), P1-C7 180.5(6); angles ( $\left.{ }^{\circ}\right)$ O O1-Ca1-O2A 92.4(1), Ca1-O1-P1 165.2(3), O1-P1-O2 119.3(2), P1-O2-Ca1A 146.7(2), I1-Ca1-O1 93.1(1), I1-Ca1-O2A 174.2(1), I1-Ca1-O3 90.6(1), I1-Ca1-O4 87.8(1), I1-Ca1-O5 92.0(1), O1-Ca1-O3 92.8(2), O1-Ca1-O4 175.8(2), O1-Ca1-O5 98.2(2), O2A-Ca1-O3 91.2(2), O2A-Ca1-O4 86.9(2), O2A-Ca1-O5 85.2(2), O3-Ca1-O4 83.1(2), O3-Ca1-O5 168.6(2), O4-Ca1-O5 85.8(2). 


\subsection{Theoretical View on Ether and Phosphane Complexes of Magnesium and Calcium Ions}

It remains puzzling that crystallization of the Grignard reagent bis(2,6-bis(diphenylphosphanyl methyl)phenyl)magnesium (2) from THF or from a mixture of THF and DME yielded solvent-free complexes. The Pearson concept of hard and soft acids and bases suggests that the hard magnesium ions prefer the hard ether bases rather than the soft phosphanes [32]. The structure of starting bromo-2,6-bis(diphenylphosphanylmethyl)benzene shows that the diphenylphosphanylmethyl side arms can turn to the side and open a coordination site at the metal center. However, entropic effects would favor intramolecular coordination of the phosphanyl moieties. In order to judge the preference of ether or phosphane coordination to magnesium ions, quantum chemical calculations, using the method B3LYP/6-311++G**, were undertaken with respect to Equation (2). The reaction enthalpies $\Delta \mathrm{H}$ for these addition reactions are listed in Table 1 . The structures of the $\left[(\mathrm{thf})_{6} \mathrm{M}\right]^{2+}$ ions are compared with those of selected X-ray structure determinations ( $\mathrm{M}=\mathrm{Mg}$ [33], $\mathrm{Ca}$ [34]) and show an excellent agreement.

$$
\left[(\mathrm{L})_{n} \mathrm{M}\right]^{2+}+\mathrm{L} \leftrightarrow\left[(\mathrm{L})_{n+1} \mathrm{M}\right]^{2+}
$$

Table 1. Reaction enthalpies $\Delta \mathrm{H}\left(\mathrm{kJ} \cdot \mathrm{mol}^{-1}\right)$ for the addition of the Lewis base $\mathrm{L}$ (thf, $\mathrm{PMe}_{3}$ ) to the metal fragment $\left[(\mathrm{L})_{n} \mathrm{M}\right]^{2+}(\mathrm{M}=\mathrm{Mg}, \mathrm{Ca})$.

\begin{tabular}{|c|c|c|c|c|c|c|}
\hline M, L & $n=0$ & $n=1$ & $n=2$ & $n=3$ & $n=4$ & $n=5$ \\
\hline $\mathrm{Mg}$, thf & -99 & -87 & -79 & -78 & -65 & -23 \\
\hline $\begin{array}{c}\mathrm{Mg}, \\
\mathrm{PMe}_{3}\end{array}$ & -104 & -82 & -52 & -37 & +43 & $-a^{a}$ \\
\hline $\mathrm{Ca}$, thf & -57 & -47 & -47 & -46 & -45 & -28 \\
\hline $\mathrm{Ca}, \mathrm{PMe}_{3}$ & -37 & -28 & -27 & -23 & -2 & -2 \\
\hline
\end{tabular}

${ }^{\text {a }}$ A complex of the type $\left[\mathrm{Mg}\left(\mathrm{PMe}_{3}\right)_{6}\right]^{2+}$ is not stable and dissociates during optimization of the structure.

The coordination of the first thf and $\mathrm{PMe}_{3}$ molecule at the naked magnesium ion $(n=0)$ shows very similar energies. Due to the larger size of trimethylphosphane, the binding energies decrease much faster for larger coordination numbers and larger $n$ values. According to these calculations, only four phosphane bases bind to the small $\mathrm{Mg}^{2+}$ cation, whereas a coordination number of six can be realized for the ether adduct. This finding is in agreement with the expectation that intramolecular repulsion between bulky ligands destabilizes complexes. The binding energies of the Lewis bases $\mathrm{L}$ to the larger alkaline earth ion $\mathrm{Ca}^{2+}$ are smaller due to larger $\mathrm{Ca}-\mathrm{L}$ distances lowering the electrostatic attraction. Unexpectedly, the reaction enthalpies for the coordination of the softer phosphane are significantly smaller than for the binding of the hard thf base, however, hexa-coordinate calcium ions are feasible for thf and $\mathrm{PMe}_{3}$ adducts. Even if steric hindrance is absent $(n=0)$, the Ca-P binding enthalpy for $\left[\mathrm{Ca}-\mathrm{PMe}_{3}\right]^{2+}$ is roughly a third smaller than for the ether adduct $[\mathrm{Ca}-\mathrm{thf}]^{2+}$.

\section{Discussion and Conclusions}

The reduction of bromo-2,6-bis(diphenylphosphanylmethyl)benzene (1a) in tetrahydrofuran requires the presence of activated magnesium, activation by iodine, and drastic reaction conditions due to the shielding of the $\mathrm{C}-\mathrm{Br}$ functionality by the ortho-bound diphenylphosphanylmethyl side arms. In solution, the heteroleptic Grignard reagent Aryl-Mg-Br and homoleptic diarylmagnesium (2) coexist. In order to shift the Schlenk equilibrium toward the homoleptic complex 2, 1,4-dioxane was added to precipitate the magnesium bromide. Recrystallization from THF or THF/DME mixtures yielded ether-free 2. Intramolecular repulsion between the diphenylphosphanyl side arms enforces an asymmetric coordination behavior leading to significantly different $\mathrm{Mg}-\mathrm{P}$ distances.

A different reaction behavior was observed for the reduction of bromo- (1a) and iodo-2,6-bis(diphenylphosphanylmethyl)benzene (1) with activated calcium in THF at room temperature. Heavy Grignard reagents of the type Aryl-Ca-Br or diarylcalcium were not accessible by this procedure, but ether degradation by arylcalcium species occurred immediately and was much 
faster than the formation of these heavy Grignard-type reagents. The enormous reactivity also led to the cleavage of the $\mathrm{P}-\mathrm{C}$ bonds to the methylene units and to oxidation reactions, finally yielding diphenylphosphinate anions. These results are in agreement with earlier studies that showed that methylation of phenylcalcium halide in 2,4,6-positions (mesitylcalcium halide) significantly enhances the reactivity, leading to faster ether degradation and also side reactions such as deprotonation of ortho-methyl groups (yielding benzyl derivatives) [35].

The quantum chemically-elucidated reaction enthalpies support the finding that ethers and phosphanes show comparable binding energies for magnesium complexes. In agreement with these findings, tetrahydrofuran and bidentate 1,2-dimethoxyethane were unable to replace the intramolecularly coordinated phosphanes in bis[2,6-bis(diphenylphosphanylmethyl)]magnesium (2), especially with additional consideration of entropic effects. A different situation can be envisioned for an isostructural calcium complex: On the one hand, ether binding is preferred compared to phosphane coordination, according to quantum chemical calculations. On the other hand, the $\mathrm{Ca}^{2+}$ ion is significantly more accessible to coordination of ether bases due to the larger size, thus easing intramolecular ether cleavage reactions via initial coordination and deprotonation steps. The preferred coordination of ethers rather than phosphanes can be understood by mainly electrostatic forces; due to significantly larger Ca-P distances the electrostatic attraction is smaller in comparison to calcium-ether interactions.

\section{Materials and Methods}

\subsection{General}

All manipulations were carried out in an inert nitrogen atmosphere using standard Schlenk techniques. The solvents were dried according to standard procedures over $\mathrm{KOH}$ and subsequently distilled over sodium/benzophenone in a nitrogen atmosphere prior to use. Deuterated solvents were dried over sodium, degassed, and saturated with nitrogen. The yields given are not optimized. ${ }^{1} \mathrm{H},{ }^{13} \mathrm{C}\left\{{ }^{1} \mathrm{H}\right\},{ }^{31} \mathrm{P}$, and ${ }^{31} \mathrm{P}\left\{{ }^{1} \mathrm{H}\right\}$ NMR spectra were recorded on Bruker $\mathrm{AC} 400$ and AC 600 spectrometers (Bruker AXS GmbH, Karlsruhe, Germany). Chemical shifts are reported in parts per million relative to $\mathrm{SiMe}_{4}$ or $85 \%$ phosphoric acid as external standards. The residual signals of the deuterated solvents were used as internal standards for ${ }^{1} \mathrm{H}$ and ${ }^{13} \mathrm{C}\left\{{ }^{1} \mathrm{H}\right\} \mathrm{NMR}$ experiments. Commercially available chemicals were purchased from Sigma-Aldrich (Sigma-Aldrich Chemie GmbH, Munich, Germany) or Alfa Aesar (Thermo Fisher GmbH, Karlsruhe, Germany). Bromo-2,6-bis(diphenylphosphanylmethyl)benzene (1a) [36,37] and Rieke magnesium [38] were prepared according to literature procedures.

\subsection{Synthesis of Iodo-2,6-bis(diphenylphosphanylmethyl)benzene (1)}

Bromo-2,6-bis(diphenylphosphanylmethyl)benzene (1a) $(5.71 \mathrm{~g}, 10.3 \mathrm{mmol})$ was suspended in a mixture of $50 \mathrm{~mL}$ of diethyl ether and $3 \mathrm{~mL}$ of TMEDA. At $-78^{\circ} \mathrm{C}, 6.78 \mathrm{~mL}$ of a $1.6 \mathrm{M} n$-butyllithium solution in hexane $(10.5 \mathrm{mmol})$ were slowly added dropwise and the reaction mixture kept at this temperature for another hour. Thereafter, the suspension was slowly heated to room temperature, resulting in a clear solution. After stirring at room temperature for another hour, $2.88 \mathrm{~g}$ of iodine, dissolved in $50 \mathrm{~mL}$ of diethyl ether, were added dropwise. During stirring overnight, a pale yellow precipitate formed. This solid was collected, dissolved in dichloromethane and washed with aqueous sodium thiosulfate solution. The organic phase was separated and dried over anhydrous sodium sulfate. The solvent was removed in vacuo. The residue was washed with acetone, leaving $1.6 \mathrm{~g}$ of 1b (25\%). ${ }^{1} \mathrm{H}$ NMR $\left(400 \mathrm{MHz}, \mathrm{CDCl}_{3}, 25^{\circ} \mathrm{C}\right): \delta 7.40-7.30(\mathrm{~m}, 8 \mathrm{H}), 7.30-7.20(\mathrm{~m}, 12 \mathrm{H}), 6.63(\mathrm{~s}, 1 \mathrm{H})$, 6.46-6.36 (m, 2H), $3.58(\mathrm{~s}, 4 \mathrm{H}) .{ }^{13} \mathrm{C}\left\{{ }^{1} \mathrm{H}\right\} \operatorname{NMR}\left(101 \mathrm{MHz}, \mathrm{CDCl}_{3}, 25^{\circ} \mathrm{C}\right): \delta 141.2\left(\mathrm{dd}, J_{\mathrm{PC}}=7.3\right.$ and $\left.1.7 \mathrm{~Hz}\right)$, $138.0\left(\mathrm{~d}, J_{\mathrm{PC}}=16.0 \mathrm{~Hz}\right), 133.2\left(\mathrm{~d}, J_{\mathrm{PC}}=19.1 \mathrm{~Hz}\right), 128.7(\mathrm{~s}), 128.4\left(\mathrm{~d}, J_{\mathrm{PC}}=6.7 \mathrm{~Hz}\right), 127.9\left(\mathrm{dd}, J_{\mathrm{PC}}=8.2\right.$ and $2.9 \mathrm{~Hz}), 126.9\left(\mathrm{t}, J_{\mathrm{PC}}=1.7 \mathrm{~Hz}\right), 109.6\left(\mathrm{t}, J_{\mathrm{PC}}=5.1 \mathrm{~Hz}\right), 43.0\left(\mathrm{~d}, J_{\mathrm{PC}}=17.2 \mathrm{~Hz}\right) .{ }^{31} \mathrm{P}\left\{{ }^{1} \mathrm{H}\right\} \mathrm{NMR}(162 \mathrm{MHz}$, $\left.\mathrm{CDCl}_{3}, 25^{\circ} \mathrm{C}\right): \delta-13.0$. 


\subsection{Synthesis of Bis(2,6-bis(diphenylphosphanylmethyl)phenyl)Magnesium (2)}

Bromo-2,6-bis(diphenylphosphanylmethyl)benzene (1a) $(3.0 \mathrm{~g}, 5.4 \mathrm{mmol})$, dissolved in $10 \mathrm{~mL}$ of THF, was added at once to a suspension of $100 \mathrm{mg}$ of magnesium (1:1 ratio of Rieke magnesium and magnesium turnings, $6.7 \mathrm{mmol}$ ) in $10 \mathrm{~mL}$ of THF. This reaction was heated under reflux and a small amount of iodine was added. The reaction mixture was stirred overnight at room temperature. After removal of all solid materials, the filtrate was cooled to $5{ }^{\circ} \mathrm{C}$. Then, 1,2-dimethoxyethane was added until all solids redissolved. Storage at $5{ }^{\circ} \mathrm{C}$ led to crystallization of 2 and $\left[(\mathrm{dme})_{2}(\mathrm{thf}) \mathrm{CaBr}_{2}\right](4)$. Acidimetric titration showed a conversion of $45 \%$; therefore, $0.8 \mathrm{~mL}$ of 1,4-dioxane were added in order to shift the Schlenk equilibrium toward the homoleptic diarylmagnesium and magnesium bromide. Within one day, a cloudy suspension formed. The solid magnesium bromides were removed and the filtrate cooled to $-20^{\circ} \mathrm{C}$, yielding $0.6 \mathrm{~g}$ of complex $2(11 \%)$. The volume of the mother liquor was reduced to half of the original volume and cooled again to $-20{ }^{\circ} \mathrm{C}$, leading to another crop of crystals of 2 (1.2 g, 22\%). Elemental analysis $\left(\mathrm{C}_{64} \mathrm{H}_{54} \mathrm{P}_{4} \mathrm{Mg}, 971.26\right)$ : calcd.: C 79.14, $\mathrm{H} 5.60$, found: $\mathrm{C} 79.27$, $\mathrm{H}$ 5.77; titration against EDTA: calcd.: $\mathrm{Mg}$ 2.50, found: $\mathrm{Mg}$ 2.7. ${ }^{1} \mathrm{H}$ NMR $\left(600 \mathrm{MHz},\left[\mathrm{D}_{8}\right] \mathrm{THF}, 25{ }^{\circ} \mathrm{C}\right): \delta$ $7.36(\mathrm{~m}, 8 \mathrm{H}), 7.17(\mathrm{t}, J=7.4 \mathrm{~Hz}, 4 \mathrm{H}), 7.01(\mathrm{t}, J=7.6 \mathrm{~Hz}, 8 \mathrm{H}), 6.81(\mathrm{t}, J=7.4 \mathrm{~Hz}, 1 \mathrm{H}), 6.68(\mathrm{~d}, J=7.4 \mathrm{~Hz}$, 2H), 3.55 (s, 8H). ${ }^{13} \mathrm{C}\left\{{ }^{1} \mathrm{H}\right\} \mathrm{NMR}\left(151 \mathrm{MHz},\left[\mathrm{D}_{8}\right] \mathrm{THF}, 25^{\circ} \mathrm{C}\right): \delta 172.0$ (m, ipso-C), 147.0, 137.2, 133.6, 129.0, $128.7,126.3,125.9,40.4 .{ }^{31} \mathrm{P}\left\{{ }^{1} \mathrm{H}\right\} \mathrm{NMR}\left(243 \mathrm{MHz},\left[\mathrm{D}_{8}\right] \mathrm{THF}, 25{ }^{\circ} \mathrm{C}\right): \delta-15.7$ (s).

\subsection{X-ray Structure Determinations}

The intensity data for the compounds were collected on a Nonius KappaCCD diffractometer (Bruker AXS GmbH) using graphite-monochromated Mo-K $\alpha$ radiation. Data were corrected for Lorentz and polarization effects; absorption was taken into account on a semi-empirical basis using multiple-scans [39-41]. The structures were solved by direct methods (SHELXS [42]) and refined by full-matrix least squares techniques against $F_{\mathrm{o}}{ }^{2}$ (SHELXL-97 [42,43] and SHELXL-2014 [44]). All hydrogen atoms bounded to the compounds 1a and 2 were located by difference Fourier synthesis and refined isotropically. All other hydrogen atoms were included at calculated positions with fixed thermal parameters. All non-hydrogen, non-disordered atoms were refined anisotropically [42-44]. The crystal of 2 was a partial-merohedral twin. The twin law was determined with PLATON [45] to $(-1.0,0.0,0.0) / 0.0,-1.0,0.0 / 0.0,0.0,1.0)$. The contribution of the main component was refined to $0.926(1)$. The crystals of 3a were extremely thin and of low quality, resulting in a substandard data set; however, the structure is sufficient to show connectivity and geometry despite the high final $R$ value. We will only publish the conformation of the molecule and the crystallographic data and will not deposit the data in the Cambridge Crystallographic Data Centre. Crystallographic data as well as structure solution and refinement details are summarized in Table S1. XP [46] and POV-Ray [47] were used for structure representations.

\subsection{Quantum Chemical Calculations}

All molecular geometry optimizations were performed with the Gaussian09 [48] suite of programs at B3LYP/6-311++G $\mathrm{G}^{* *}$ [49-52] level of theory. Vibrational analysis was performed at the same level of theory to confirm the nature of local structure minima. The basis set superposition errors were computed with the keyword "counterpoise".

Supplementary Materials: The following are available online at: www.mdpi.com/2304-6740/4/4/39/s1, Table S1: Crystal data and refinement details for the X-ray structure determinations of the compounds 1a, $2,3 a, 3 b$, and 4 . Cartesian coordinates of calculated structures. Crystallographic data (excluding structure factors) has been deposited with the Cambridge Crystallographic Data Centre as supplementary publication CCDC-1509090 for 1a, CCDC-1509091 for 2, CCDC-1509092 for 3b, and CCDC-1509093 for 4. Copies of the data can be obtained free of charge on application to CCDC, 12 Union Road, Cambridge CB2 1EZ, UK (E-mail: deposit@ccdc.cam.ac.uk).

Acknowledgments: We acknowledge the financial support by the Verband der Chemischen Industrie e.V. (FCI/VCI, Frankfurt/Main, Germany; fund No. 510259); Alexander Koch is grateful to the Verband der Chemischen Industrie e.V. $(F C I / V C I)$ for a generous Ph.D grant. 
Author Contributions: Alexander Koch, Sven Krieck, and Matthias Westerhausen conceived and designed the experiments; Alexander Koch performed the experiments; Alexander Koch, Sven Krieck, and Matthias Westerhausen analyzed the data; Helmar Görls carried out the X-ray crystal structure determinations and the interpretation of the crystal data; Alexander Koch performed all quantum chemical calculations; all authors contributed to the manuscript.

Conflicts of Interest: The authors declare no conflict of interest.

\section{References}

1. Maercker, A. Ether Cleavage with Organo-Alkali-Metal Compounds and Alkali Metals. Angew. Chem. Int. Ed. Engl. 1987, 26, 972-989. [CrossRef]

2. Langer, J.; Krieck, S.; Fischer, R.; Görls, H.; Walther, D.; Westerhausen, M. 1,4-Dioxane Adducts of Bis(2,4,6-trimethylphenyl)magnesium: Synthesis, Ether Cleavage Reactions, and Structural Diversity of Grignard Reagent/1,4-Dioxane Complexes. Organometallics 2009, 28, 5814-5820. [CrossRef]

3. Krieck, S.; Westerhausen, M. Reimagining the Grignard Reaction. In The Lightest Metals: Science and Technology from Lithium to Calcium (Encyclopedia of Inorganic and Bioinorganic Chemistry); Hanusa, T.P., Ed.; Wiley: Chichester, UK, 2015; pp. 213-229.

4. Westerhausen, M.; Langer, J.; Krieck, S.; Fischer, R.; Görls, H.; Köhler, M. Heavier Group 2 Grignard Reagents of the Type Aryl-Ae(L) $n_{n}-\mathrm{X}$ (Post-Grignard-Reagents). Top. Organomet. Chem. 2013, 45, 29-72. [CrossRef]

5. Westerhausen, M.; Langer, J.; Krieck, S.; Glock, C. Calcium-based Organometallics and Superbases-Alkyl-, Aryl-, and Amidocalcium Compounds. Rev. Inorg. Chem. 2011, 31, 143-184.

6. Buchanan, W.D.; Allis, D.G.; Ruhlandt-Senge, K. Synthesis and Stabilization-Advances in Organoalkaline Earth Metal Chemistry. Chem. Commun. 2010, 46, 4449-4465. [CrossRef] [PubMed]

7. Westerhausen, M. Recent Developments in Organic Chemistry of Calcium-An Element with Unlimited Possibilities in Organometallic Chemistry? Z. Anorg. Allg. Chem. 2009, 635, 13-32. [CrossRef]

8. Westerhausen, M. Heavy Grignard Reagents-Synthesis and Reactivity of Organocalcium Compounds. Coord. Chem. Rev. 2008, 252, 1516-1531. [CrossRef]

9. Westerhausen, M.; Gärtner, M.; Fischer, R.; Langer, J. Arylcalcium Compounds: Syntheses, Structures, Physical Properties, and Chemical Behaviour. Angew. Chem. Int. Ed. 2007, 46, 1950-1956. [CrossRef] [PubMed]

10. Westerhausen, M.; Gärtner, M.; Fischer, R.; Langer, J.; Yu, L.; Reiher, M. Heavy Grignard Reagents: Challenges and Possibilities of Aryl Alkaline Earth Metal Compounds. Chem. Eur. J. 2007, 13, 6292-6306. [CrossRef] [PubMed]

11. Köhler, M.; Koch, A.; Görls, H.; Westerhausen, M. Trimethylsilylmethylcalcium Iodide, an Easily Accessible Grignard-Type Reagent of Calcium. Organometallics 2016, 35, 242-248. [CrossRef]

12. Meinholz, M.M.; Pandey, S.K.; Deuerlein, S.M.; Stalke, D. Access to New Janus Head Ligands: Linking Sulfur Diimides and Phosphanes for Hemilabile Tripodal Scorpionates. Dalton Trans. 2011, 40, 1662-1671. [CrossRef] [PubMed]

13. Peitz, S.; Peulecke, N.; Aluri, B.R.; Müller, B.H.; Spannenberg, A.; Rosenthal, U.; Al-Hazmi, M.H.; Mosa, F.M.; Wöhl, A.; Müller, W. Metalation and Transmetalation Studies on $\mathrm{Ph}_{2} \mathrm{PN}\left({ }^{i} \mathrm{Pr}\right) \mathrm{P}(\mathrm{Ph}) \mathrm{N}\left({ }^{i} \mathrm{Pr}\right) \mathrm{H}$ for Selective Ethene Trimerization to 1-Hexene. Organometallics 2010, 29, 5263-5268. [CrossRef]

14. Pape, A.; Lutz, M.; Müller, G. Phosphane Coordination to Magnesium: Synthesis and Structure of Bis[ortho,ortho'-bis\{(dimethylphosphino)methyl $\}$ phenyl]magnesium. Angew. Chem. Int. Ed. Engl. 1994, 33, 2281-2284. [CrossRef]

15. Karsch, H.H.; Reisky, M. Phosphane Complexes of Alkaline Earth Metals. Eur. J. Inorg. Chem. 1998, 905-911. [CrossRef]

16. Westerhausen, M.; Digeser, M.H.; Schwarz, W. 1,3-Bis(trimethylsilyl)-2-phenyl-1-aza-3-phosphapropenide Anions as Bidentate Ligands for the Alkaline Earth Metals Magnesium, Calcium, Strontium, and Barium. Inorg. Chem. 1997, 36, 521-527. [CrossRef]

17. Meinholz, M.M.; Stalke, D. Monoanionic N,P,S-Janus Head Tripods in s-Block Metal Coordination. Eur. J. Inorg. Chem. 2011, 2011, 4578-4584. [CrossRef]

18. Langer, J.; Wimmer, K.; Görls, H.; Westerhausen, M. Synthesis and Crystal Structures of Bis(diphenylphosphanyl)methanides of Lithium and Calcium as well as of their Borane Adducts. Dalton Trans. 2009, 28, 2951-2957. [CrossRef] [PubMed] 
19. Knapp, V.; Müller, G. Cyclopentadienyl-Free Calcium Alkyls with Heteroelement-Substituted Anionic Phosphane Ligands: Synthesis and Structure of a Trialkyl Calcate(II) and of an Organocalcium Heterocubane. Angew. Chem. Int. Ed. 2001, 40, 183-186. [CrossRef]

20. Markies, P.R.; Akkerman, O.S.; Bickelhaupt, F.; Smeets, W.J.J.; Spek, A.L. X-ray Structural Analyses of Organomagnesium Compounds. Adv. Organomet. Chem. 1991, 32, 147-226.

21. Holloway, C.E.; Melnik, M. Magnesium Compounds: Classification and Analysis of Crystallographic and Structural Data. J. Organomet. Chem. 1994, 465, 1-63. [CrossRef]

22. Uhm, H.L. Crystal Structures of Grignard Reagents. In Handbook of Grignard Reagents; Silverman, G.S., Rakita, P.E., Eds.; CRC Press: Boca Raton, FL, USA, 1996; pp. 117-144.

23. Bickelhaupt, F. Structures of Organomagnesium Compounds as Revealed by X-ray Diffraction Studies. In Grignard Reagents: New Developments; Richey, H.G., Ed.; Wiley: Chichester, UK, 2000; pp. 299-328.

24. Jastrzebski, J.T.B.H.; Boersma, J.; van Koten, G. Structural Organomagnesium Chemistry. In The Chemistry of Organomagnesium Compounds (Patai Series: The Chemistry of Functional Groups); Wiley: Chichester, UK, 2008; pp. 1-99.

25. Ruspic, C.; Harder, S. Synthesis and Structure of an Arylcalcium Compound with an Unusual Calcium Tetrahedron Containing an Encapsulated Oxide. Organometallics 2005, 24, 5506-5508. [CrossRef]

26. Fischer, R.; Görls, H.; Westerhausen, M. Reinvestigation of the Synthesis of Phenylcalcium Iodide and the First Structural Characterization of a Heavy Grignard Reagent as $\left[\left((\text { thf })_{2} \mathrm{CaPhI}\right)_{3} \cdot(\right.$ thf $\left.) \mathrm{CaO}\right]$ with a Central $\mathrm{Ca}_{4}$ Tetrahedron. Inorg. Chem. Commun. 2005, 8, 1159-1161. [CrossRef]

27. Gärtner, M.; Görls, H.; Westerhausen, M. Heteroleptic Phenylcalcium Derivatives via Metathesis Reaction of $\mathrm{PhCa}(\text { thf })_{4} \mathrm{I}$ with Potassium Compounds. Organometallics 2007, 26, 1077-1083. [CrossRef]

28. Krieck, S.; Görls, H.; Westerhausen, M. Reactivity Studies of Phenylcalcium Iodide Towards THF Yielding Phenyl-Free Cage Compounds-Crystal Structures of $\left[\left\{(\text { thf }) \mathrm{Ca}\left(\mathrm{O}-\mathrm{CH}=\mathrm{CH}_{2}\right)_{2}\right\}_{4} \cdot \mathrm{CaO} \cdot \mathrm{CaI}_{2}\right]$ and $\left[(\mathrm{CaO})_{4} \cdot 4(\text { thf })_{3} \mathrm{CaI}_{2}\right]$. J. Organomet. Chem. 2009, 694, 2204-2209. [CrossRef]

29. Al-Shboul, T.M.A.; Volland, G.; Görls, H.; Krieck, S.; Westerhausen, M. Oxidation Products of Calcium and Strontium Bis(diphenylphosphanide). Inorg. Chem. 2012, 51, 7903-7912. [CrossRef] [PubMed]

30. Westerhausen, M.; Krieck, S.; Langer, J.; Al-Shboul, T.M.A.; Görls, H. Phosphanides of Calcium and Their Oxidation Products. Coord. Chem. Rev. 2013, 257, 1049-1066. [CrossRef]

31. Langer, J.; Krieck, S.; Fischer, R.; Görls, H.; Westerhausen, M. Post-Grignard Reagents: Influence of the Coligands $\mathrm{L}$ on the Molecular Structures of Phenylcalcium Iodides $\left[(\mathrm{L})_{n} \mathrm{Ca}(\mathrm{R}) \mathrm{I}\right]$ and Calcium Diiodides [(L) $\left.{ }_{n} \mathrm{CaI}_{2}\right]$. Z. Anorg. Allg. Chem. 2010, 636, 1190-1198. [CrossRef]

32. Burt, J.; Levason, W.; Reid, G. Coordination Chemistry of the Main Group Elements with Phosphine, Arsine and Stibine Ligands. Coord. Chem. Rev. 2014, 260, 65-115. [CrossRef]

33. Michel, O.; Meermann, C.; Törnroos, K.W.; Anwander, R. Alkaline-Earth Metal Alkylaluminate Chemistry Revisited. Organometallics 2009, 28, 4783-4790. [CrossRef]

34. Krieck, S.; Görls, H.; Westerhausen, M. Synthesis and Properties of Calcium Tetraorganylalanates with $\left[\mathrm{Me}_{4-n} \mathrm{AlPh}_{n}\right]^{-}$Anions. Organometallics 2008, 27, 5052-5057. [CrossRef]

35. Fischer, R.; Gärtner, M.; Görls, H.; Westerhausen, M. Synthesis of 2,4,6-Trimethylphenylcalcium Iodide and Degradation in THF Solution. Angew. Chem. Int. Ed. 2006, 45, 609-612. [CrossRef] [PubMed]

36. Dilworth, J.R.; Zheng, Y.; Griffiths, D.V. Binuclear Complexes with Ligands Based on the 2,6-Bis(diphenylphosphinomethyl)benzene Framework. Synthesis and Crystal Structures of $\left[\mathrm{Ir}_{2} \mathrm{Cl}_{2}(\mu-\mathrm{CO})\left\{2,6-\left(\mathrm{Ph}_{2} \mathrm{PCH}_{2}\right)_{2} \mathrm{C}_{6} \mathrm{H}_{3} \mathrm{~S}\right\}_{2}\right] \cdot 2 \mathrm{CH}_{2} \mathrm{Cl}_{2}$ ， [Ni 2 \{2,6- $\left.\left.\left(\mathrm{Ph}_{2} \mathrm{PCH}_{2}\right)_{2} \mathrm{C}_{6} \mathrm{H}_{3} \mathrm{~S}\right\}_{2}\right] \cdot \mathrm{Et}_{2} \mathrm{O} \cdot 0.5 \mathrm{CH}_{2} \mathrm{Cl}_{2}$ and $\left[\mathrm{Rh}_{2} \mathrm{Cl}_{2}(\mathrm{CO})_{2}\left\{1,3-\left(\mathrm{Ph}_{2} \mathrm{PCH}_{2}\right)_{2} \mathrm{C}_{6} \mathrm{H}_{4}\right\}_{2}\right]$. J. Chem. Soc. Dalton Trans. 1999, 1877-1881. [CrossRef]

37. Rieke, R.D. Preparation of Highly Reactive Metal Powders and Their Use in Organic and Organometallic Synthesis. Acc. Chem. Res. 1977, 10, 301-306. [CrossRef]

38. Rieke, R.D. Preparation of Organometallic Compounds from Highly Reactive Metal Powders. Science 1989, 246, 1260-1264. [CrossRef] [PubMed]

39. Hooft, R. COLLECT, Data Collection Software, Nonius B.V.: Rotterdam, The Netherlands, 1998.

40. Otwinowski, Z.; Minor, W. Processing of X-ray Diffraction Data Collected in Oscillation Mode. In Methods in Enzymology, Macromolecular Crystallography; Carter, C.W., Sweet, R.M., Eds.; Academic Press: New York, NY, USA, 1997; Volume 276, pp. 307-326.

41. SADABS 2.10; Bruker-AXS Inc.: Madison, WI, USA, 2002.

42. Sheldrick, G.M. A Short History of SHELX. Acta Cryst. 2008, A64, 112-122. [CrossRef] [PubMed] 
43. Spek, A.L. Structure Validation in Chemical Crystallography. Acta Cryst. 2009, D65, 148-155. [CrossRef] [PubMed]

44. Sheldrick, G.M. Crystal Structure Refinement with SHELXL. Acta Cryst. 2015, C71, 3-8.

45. Spek, A.L. PLATON SQUEEZE: A Tool for the Calculation of the Disordered Solvent Contribution of the Calculated Structure Factors. Acta Cryst. 2015, C71, 9-18.

46. XP Molecular Graphics Software; Siemens Analytical X-ray Instruments Inc.: Karlsruhe, Germany, 1990; Madison, WI, USA, 1994.

47. POV-Ray; Persistence of Vision Raytracer: Williamstown, Australia, 2007.

48. Frisch, M.J.; Trucks, G.W.; Schlegel, H.B.; Scuseria, G.E.; Robb, M.A.; Cheeseman, J.R.; Scalmani, G.; Barone, V.; Mennucci, B.; Petersson, G.A.; et al. Gaussian 09, Revision A.02, Gaussian, Inc.: Wallingford, UK, 2009.

49. Becke, A.D. Density-Functional Thermochemistry. III. The Role of Exact Exchange. J. Chem. Phys. 1993, 98, 5648-5652. [CrossRef]

50. Becke, A.D. Density-Functional Exchange-Energy Approximation with Correct Asymptotic Behavior. Phys. Rev. A 1988, 38, 3098-3100. [CrossRef]

51. Lee, C.; Yang, W.; Parr, R.G. Development of the Colle-Salvetti Correlation-Energy Formula into a Functional of the Electron Density. Phys. Rev. B 1988, 37, 785-789. [CrossRef]

52. Hariharan, P.C.; Pople, J.A. The Influence of Polarization Functions on Molecular Orbital Hydrogenation Energies. Theor. Chem. Acc. 1973, 28, 213-222. [CrossRef]

(C) 2016 by the authors; licensee MDPI, Basel, Switzerland. This article is an open access article distributed under the terms and conditions of the Creative Commons Attribution (CC-BY) license (http://creativecommons.org/licenses/by/4.0/). 